Revista Brasileira de Agricultura Irrigada v.8, no. 2, p. 98 - 105, 2014

ISSN 1982-7679 (On-line)

Fortaleza, CE, INOVAGRI - http://www.inovagri.org.br

DOI: $10.7127 /$ rbai.v8n200228

Protocolo 228/14 - 09/09/2013 Aprovado em 17/03/2014

\title{
QUALIDADE DA ÁGUA NO RIACHO JACARÉ, SERGIPE BRASIL USADA PARA IRRIGAÇÃO
}

Ariovaldo Antonio Tadeu Lucas ${ }^{1}$, Ana Sheila Alves Moura ${ }^{2}$, Antenor De Oliveira Aguiar Netto $^{3}$, Gregorio Guirado Faccioli ${ }^{4}$, Inajá Francisco De Sousa ${ }^{5}$

\section{RESUMO}

Estudou-se a qualidade da água usada na irrigação da cultura de arroz por inundação, captada do riacho Jacaré, afluente do rio São Francisco no estado de Sergipe. As coletas de amostras de água ocorreram nos meses de abri, julho, agosto e outubro de 2011 em seis pontos ao longo do riacho Jacaré, e os parâmetros avaliados foram $\mathrm{pH}$, condutividade elétrica, sódio, cloreto, potássio, cálcio, magnésio, nitrato e sólidos totais. A metodologia usada nas análises foi recomendada pela APHA e realizadas no laboratório de Química Ambiental da Universidade Federal de Sergipe. Os resultados mostraram que a condutividade elétrica, o potássio e o nitrato foram os parâmetros que apresentaram valores fora do estabelecido para a água usada na irrigação. Concluiu-se que mesmo com valores fora do estabelecido para os parâmetros: condutividade elétrica, potássio e nitrato a água do riacho Jacaré ainda não apresenta risco de salinização do solo, bem como compromete o ecossistema aquático.

Palavras-chaves: bacia hidrográfica, cultivo de arroz, salinização do solo

\section{WATER QUALITY IN JACARÉ STREAM, SERGIPE BRAZIL, USED FOR IRRIGATION}

\begin{abstract}
The water quality used to irrigate rice crop was studied; it is withdraw from Jacare stream, tributary of São Francisco River at the Sergipe State. Water samples were collected in April, July, August and October of 2011 in six stations along of Jacaré stream and pH, electric conductivity, sodium, potassium, calcium, magnesium, nitrate and total solid suspense were the parameters analyzed. The methodology used to analyze the parameters is according to APHA and determinate in Environmental Chemistry Laboratory of Federal University of

\footnotetext{
${ }^{1}$ Professor Doutor DEA - Universidade Federal de Sergipe. Email: aatlucas@ gmail.com

${ }^{2}$ Mestre em Desenvolvimento e Meio Ambiente - UFS. Email: ana_moura2005@ hotmail.com

${ }^{3}$ Professor Doutor DEA - Universidade Federal de Sergipe. Email: antenor.ufs@ gmail.com

${ }^{4}$ Professor Doutor DEA - Universidade Federal de Sergipe. Email: gregorioufs@ mail.com

${ }^{5}$ Professor Doutor DEA - Universidade Federal de Sergipe. Email: inajafrancisco@ gmail.com
} 
Sergipe. The results showed that the electric conductivity, potassium and nitrate were the parameters that presented values out of established for water used for irrigation. It was concluded that even with values outside of established parameters for electrical conductivity, potassium and nitrate the water from the Jacare stream yet not presents risk of soil salinization, and commits the aquatic ecosystem.

Keywords: watershed, crop rice, soil salinization

\section{INTRODUÇÃO}

Os ecossistemas aquáticos continentais são utilizados no Brasil e no mundo como recursos disponíveis para a sociedade, com significado ecológico, econômico e social (Tundisi et al., 2006). As finalidades de uso são múltiplas, entre as quais se destacam o abastecimento público de água, a geração de energia elétrica, a irrigação, a aquicultura, a dessedentação animal e a harmonia paisagística. Nos últimos anos os recursos hídricos vêm sendo modificados por ação antrópica, resultando em prejuízo na qualidade e disponibilidade de água, sendo notória a necessidade crescente do monitoramento das alterações na qualidade de água, de forma a não comprometer seu aproveitamento múltiplo e minimizar os impactos negativos do ambiente. (Braga et al., 2006)

O crescimento demográfico, implicando em maiores demandas de alimento é um delicado problema que preocupa a todos os países, constituindo-se em um sério desafio científico-tecnológico. Ao setor agropecuário cabe a tarefa de fornecer alimentos à humanidade, em níveis crescentes de quantidade e qualidade. A irrigação, sobretudo nas regiões áridas e semiáridas, constitui-se em uma das mais importantes tecnologias para o aumento da produtividade e garantia da produção agrícola (Machado et al, 2007)

Neste contexto, pode-se afirmar que a irrigação no Nordeste brasileiro é uma excelente alternativa para promover a ocupação e o aproveitamento econômico das regiões semiáridas. Com essa finalidade foram implantados diversos perímetros irrigados na região. Contudo, a prática da agricultura irrigada, apesar dos seus êxitos, quando má empregada pode provocar o surgimento de vários problemas, dentre os mais graves destaca-se a salinização dos solos, que diminui a produtividade da maioria das culturas e, contribui para o processo de possível desertificação.

A crescente contaminação dos recursos hídricos, causada por diversas fontes, dentre as quais se destacam os efluentes domésticos, os efluentes industriais e a carga difusa urbana e agrícola, vem comprometendo o uso desses recursos para os seus diversos fins. Cada uma 
dessas fontes possui características próprias quanto aos poluentes. A poluição das águas por efluentes domésticos e industriais é uma das maiores causas da redução na qualidade da água, aumentando os custos de tratamento para consumo humano. Dessa forma, a avaliação e o monitoramento da água são fundamentais para acompanhar o comportamento dos parâmetros físico-químicos, alem de fornecer subsídios para avaliar as condições do manancial e contribuir com informações para tomada de decisões no gerenciamento dos recursos hídricos (Figueirêdo, 2008).

Com a restrição cada vez maior do uso de reservas de água doce no Planeta, provocado pelo crescente uso indevido desse recurso natural e pela degradação ambiental que está acelerada e comprometendo os mananciais, as reservas hídricas vêm sendo utilizadas de forma prejudicial e irreversível, havendo necessidade de ações que visem o gerenciamento de bacias hidrográficas e mananciais. Devido à situação atual dos recursos naturais encontrarem-se degradados pela ação do homem através da ocupação urbana indevida e atividades agropecuárias, a sub-bacia hidrográfica do riacho Jacaré apresenta um cenário ideal para se estudar os efeitos destas atividades. Esta subbacia é de suma importância, pois as águas do riacho abastecem os municípios de Telha, Cedro de São João e Propriá, os projetos de irrigação (hortaliças, plantações de arroz), criatórios de peixes, os quais propicia o suprimento do comércio interno da região. Dessa forma, compreende-se a importância da pesquisa, tendo em vista a contribuição para o desenvolvimento sustentável dessas atividades.

Portanto, este trabalho teve por objetivo avaliar a qualidade físico-química da água do riacho Jacaré considerando as atividades de rizicultura, piscicultura, suinocultura e a bovinocultura de corte.

\section{MATERIAL E MÉTODO}

\section{Descrição da área de estudo}

A sub-bacia do rio Jacaré está situada na porção Norte do Estado de Sergipe, ocupando uma área de aproximadamente $326 \mathrm{Km}^{2}$, o riacho Jacaré é afluente da margem direita do rio São Francisco, abrange os municípios 4 sergipanos.

As condições climatológicas têm sido consideradas na dinâmica do meio ambiente, pois o fornecimento de calor e umidade, sobretudo, desencadeia processos no geossistema, levando à formação dos solos, aos processos morfológicos, aos recursos hídricos, inclusive repercutindo nas atividades econômicas (Fontes, 2003).

As condições climáticas da sub-bacia hidrográfica do riacho Jacaré é semiárido com estação seca no verão, com evapotranspiração potencial média anual superior a precipitação média anual, com temperaturas sempre superiores aos $18^{\circ} \mathrm{C}$ e amplitude térmica mensal 
menor que $5^{\circ} \mathrm{C}$ (Brasil, 1998). A área localizarse em uma faixa de transição entre o clima agreste e o semiárido, além das próprias características do solo que podem influenciar na cobertura vegetal.

O comportamento pluviométrico das chuvas apresenta máximas nos meses de abril a julho com uma média de $124 \mathrm{~mm}$. Ausência de precipitações foi registrada nos meses de novembro a fevereiro com uma média de 28,2 $\mathrm{mm}$, constituindo-se nos meses mais secos da série estudada.

\section{Coleta e análise dos dados}

As coletas foram realizadas nos meses de Abril, Julho, Agosto e Outubro de 2011, ao longo do curso do riacho Jacaré. Elas foram realizadas em período seco e chuvoso, sendo as amostras de água obtidas em seis pontos, os quais estão descritos na Tabela 1.

Tabela 1 - Localização dos pontos de amostragem de água para análise da qualidade.

\begin{tabular}{ccc}
\hline Ponto & $\begin{array}{c}\text { Coordenadas } \\
(\text { UTM })\end{array}$ & Situação \\
\hline \multirow{2}{*}{1} & $\begin{array}{c}0726945 \\
8852352\end{array}$ & $\begin{array}{c}\text { Captação de água para } \\
\text { abastecimento público }\end{array}$ \\
& 0727482 & Nascente \\
2 & 8853860 & Riacho Jacaré que atravessa \\
& 0727358 & a propriedade rural \\
3 & 8854020 & Próximo de povoado e \\
& 0728568 & Fazendas \\
4 & 8861190 & Ponte sobre o Riacho Jacaré \\
& 0731174 & em munícipio Cedro de São \\
& 8866502 & João; \\
5 & 0736292 & Encontro do Riacho Jacaré \\
& 8870872 & com o São Francisco - FOZ. \\
\hline
\end{tabular}

Todas as amostras foram coletadas em frasco plástico branco com capacidade de 1L para as análises de pH, Condutividade, Cloreto, Sódio, Potássio, Cálcio, Magnésio, Nitrato, Sólidos Totais. As análises foram realizadas de acordo com APHA (1995), no laboratório de Química Analítica Ambiental da Universidade Federal de Sergipe (UFS).

As temperaturas medidas em cada ponto variaram entre $26^{\circ} \mathrm{C}$ a $30^{\circ} \mathrm{C}$. Este indicador está relacionado com o aumento do consumo de água, com a solubilidade e ionização das substâncias coagulantes e com a mudança do $\mathrm{pH}$.

Vale lembrar que os lançamentos de esgotos não tratados também podem contribuir para a presença de sais dissolvidos.

Os dados foram analisados segundo a estatística descritiva (média, máximo, mínimo e porcentagem). Os dados obtidos foram considerados em função dos pontos e períodos de coleta.

\section{RESULTADOS E DISCUSSÕES}

Os valores dos parâmetros gerais da água, $\mathrm{pH}$, Condutividade $\left(\mu \mathrm{S} \mathrm{cm}^{-1}\right)$, Cloreto, Sódio, Potássio, Cálcio, Magnésio, Nitrito, Nitrato, Sólidos Totais (mg/L), são apresentados e discutidos com base em diretrizes nacionais e internacionais de qualidade da água para irrigação. 
Durante os períodos estudados, os valores de $\mathrm{pH}$ variaram de 5,2 a 7,4 no mês de Abril; de 4,7 a 7,58 em Julho; de 5,7 a 8,5 em Agosto e de 5,9 a 8,6 em Outubro.

Não se observou entre as campanhas, uma variação considerável nos valores do $\mathrm{pH}$ da água. De acordo com os valores de $\mathrm{pH}$ apresentados, o ponto 2 está indicando o menor valor, variando entre de 4,7 a 5,9 na coleta do mês de abril a Outubro. Os pontos avaliados mantiveram o pH acima de 6,0 e menor que 8,5 conferindo o aspecto alcalino a esse corpo hídrico. Com base na estatística básica, as médias desses valores são de 6,5 a 8,5, enquadrando-se ao limite estabelecido pela Resolução CONAMA, n 357 de 17 março de 2005, para as classes 1 e 2 .

Os maiores registros para a condutividade elétrica ocorreram nos pontos 4, 5 e 6 (Figura 1), devido ao acúmulo de matérias acrescentado ao corpo hídrico mediante a precipitação ocorrida nesta estação associado as perdas de solos que atingem o riacho. Provavelmente houve uma redução da vazão que propiciou num aumento da concentração de íons, aumentando, assim, a condutividade elétrica. Os valores estabelecidos pela Resolução do CONAMA, no 357 de 17 de março de 2005, para condutividade em água, pode variar de 10 a $1000 \mu{\mathrm{S} . \mathrm{cm}^{-1}}^{-}$.

Em geral, níveis superiores a $100 \mu \mathrm{S} . \mathrm{cm}^{-1}$ indicam ambientes impactados. A condutividade também fornece uma boa indicação das modificações na composição de uma água, especialmente na sua concentração mineral, mas não fornece nenhuma indicação das quantidades relativas dos vários componentes. A condutividade elétrica da água está diretamente ligada ao aporte de sólidos dissolvidos adicionados com o carreamento de solos ao corpo hídrico, de acordo com CETESB(2009), altos valores podem conferir a água características corrosivas da água.

Para a irrigação o principal problema é o excesso de sais na água, pois o seu acúmulo no solo à medida que a água evapora, pode resultar em salinização do solo. $\mathrm{O}$ aumento da salinidade no solo ocasionar a redução no rendimento das culturas e provoca até mesmo a sua morte, no caso da cultura apresentar baixa sensibilidade ao sal. Salienta-se ainda que a salinização é um fator de impacto ao meio ambiente, especialmente quando a irrigação não é eficiente e a água tem uma qualidade baixa (Cai et al., 2003; Ji et al., 2006; Tanji \& Kielen, 2002).

As concentrações de nitrato nos pontos P1, P2 e P3nos meses de Abril, Julho e Outubro, P4 nos meses de Agosto e Outubro, P5 e P6 em Abril e Outubro (Figura 1), estiveram no limite ou superior ao que é permitido pelo CONAMA e, no ponto P6 nos meses de Julho e Agosto ficaram abaixo da média, isto é, abaixo de 0,70 $\mathrm{mgL}^{-1}$ limite estabelecido pelo CONAMA $357 / 2005$ para a classes 1 e 2 . É notório ao longo do curso do riacho Jacaré plantas aquáticas devido aos teores de nitrato acima de $0,70 \mathrm{mg} \mathrm{L}^{-1}$ que podem favorecer o crescimento dessas espécies de plantas, causando a contaminação da água pelo nitrogênio oriundo da fertilização e que em casos extremos causa eutrofização e hipóxia nos ecossistemas aquáticos (Lorite-Herrera and JimenezEspinosa, 2008; Kizuka et al., 2008; Scavia \& Bricker, 2006) 
Lucas et al.
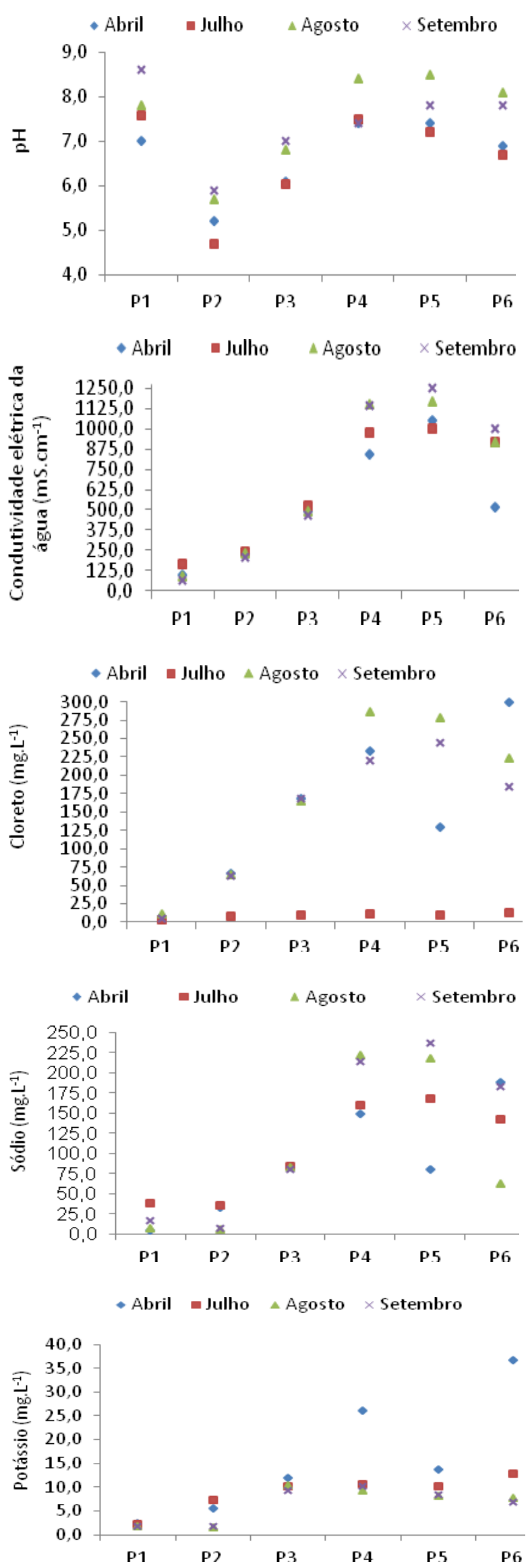
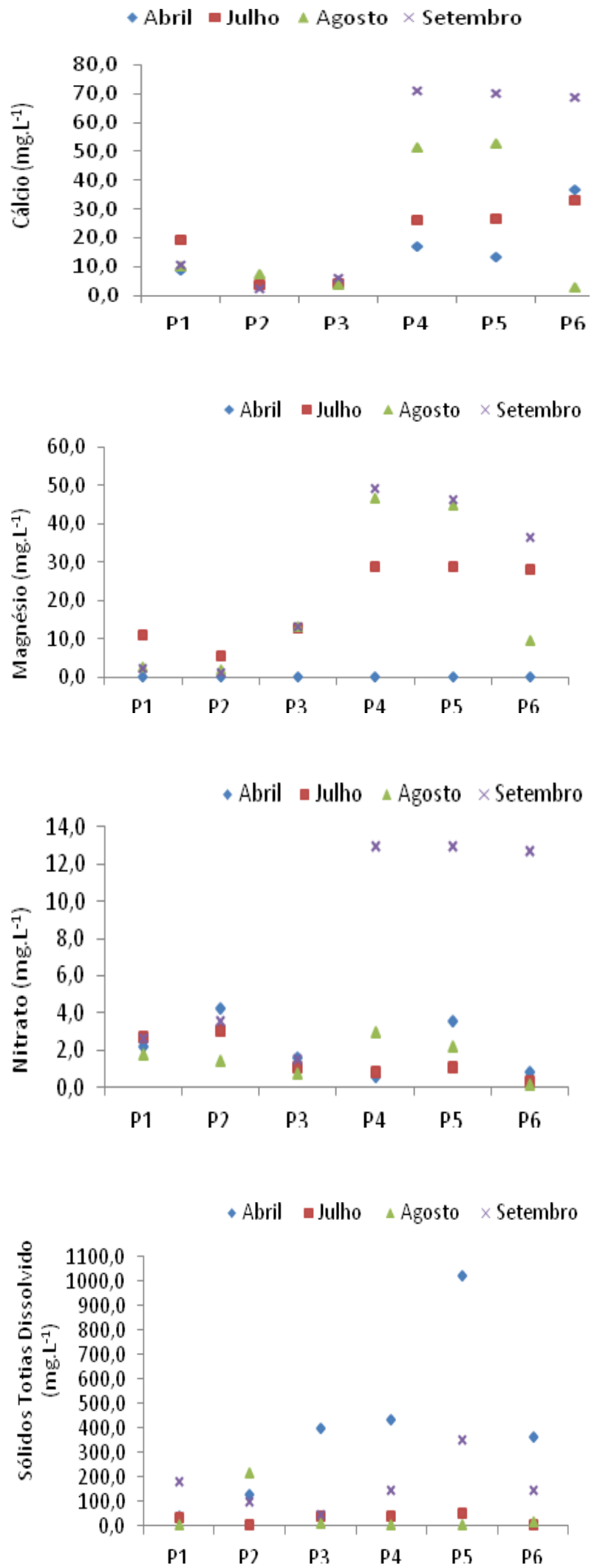

Figura 1: Variação do $\mathrm{pH}$, Condutividade elétrica da água, cloreto, sódio, potássio, cálcio, magnésio, Nitrato e sólidos totais dissolvidos. 
O nitrogênio pode estar presente na água sob várias formas: molecular, amônia, nitrito, nitrato; é um elemento indispensável ao crescimento de algas, mas, em excesso, pode ocasionar um exagerado desenvolvimento desses organismos, fenômeno chamado de eutrofização.

O valor de sólidos totais dissolvidos no Ponto 5 ficou em $1.020,00 \mathrm{mg} / \mathrm{L}$ no mês de Abril, ultrapassando o limite máximo permitido pelo CONAMA que é de $500 \mathrm{mg} / \mathrm{L}$. As elevadas concentrações de Sólidos Totais Dissolvidos (STD) observadas evidenciam a existência da influência de um agente externo, provavelmente associado à drenagem terrestre e relacionado com o manejo do solo na região estudada.

O sódio é um dos elementos mais abundantes na terra e é um sal solúvel, por isso toda água natural contém sódio. Em alguns pontos, porém, as concentrações de sódio estão bem abaixo de $50 \mathrm{mg} / \mathrm{L}$. Nas amostras das coletas de água o sódio variou de $4,43 \mathrm{mg} / \mathrm{L}$ a 236,98 mg/L; as menores concentrações foram observadas em Abril (P1=5,13mg/L), Agosto $(\mathrm{P} 1=7,11 \mathrm{mg} / \mathrm{L}$ e $\mathrm{P} 2=5,56 \mathrm{mg} / \mathrm{L})$ e Outubro (P1= 4,43 mg/L e P2=7,18 mg/L).

As concentrações de potássio ficaram entre 1,56 e $36,67 \mathrm{mg} / \mathrm{L}$ em todos os pontos coletados na região (Figura 1). As concentrações de potássio, em águas naturais, são baixas, pois as rochas que contêm potássio são relativamente resistentes ao intemperismo.

Cálcio e magnésio são elementos comuns em águas naturais, originários de rochas calcárias e de rochas contendo minerais ferromagnésio. O cálcio é um elemento nutricional, essencial à vida animal, elevadas concentrações são relativamente inofensivas ao organismo. As concentrações de cálcio variaram de 2,28 a
$70,92 \mathrm{mg} / \mathrm{L}$, a menor concentração foi medida no mês de Outubro, no ponto 2 e a maior concentração no ponto 4 do mesmo mês. O cálcio é um dos "elementos maiores" responsáveis pela dureza da água. Água com cálcio menor que $60 \mathrm{mg} / \mathrm{L}$ é considerada água mole.

O magnésio é também essencial à vida um adulto requer diariamente cerca de 200 a $300 \mathrm{mg}$ de $\mathrm{Mg}$. Ele não exerce efeito danoso à saúde e à vida aquática, mas presente em grande quantidade imprime gosto amargo à água. As concentrações de magnésio variaram de 1,23 a $49,36 \mathrm{mg} / \mathrm{L}$. O menor e o maior valor foram registrados na coleta de Outubro, nos pontos $2 \mathrm{e}$ 4 , respectivamente.

Os cloretos, geralmente, provêm da dissolução de minerais ou da intrusão de águas do mar, pela deposição de efluentes industriais e urbanos e pelo intemperismo de rochas sedimentares. O limite pela resolução vigente CONAMA 357/2005 é de 250mg/ L; concentrações excessivas de cloreto não têm efeito nocivo, sendo o limite estabelecido, principalmente, em função do seu potencial corrosivo. As concentrações de cloreto ficaram entre 4,43 e 299,26 mg/L. Em altas concentrações, conferem sabor salgado à água ou propriedades laxativas.

\section{CONCLUSÃO}

Os resultados permitem concluir que mesmo com valores fora do estabelecido para os parâmetros: condutividade elétrica, potássio e nitrato a água do riacho Jacaré ainda não apresenta risco de salinização do solo, bem como 
compromete o ecossistema aquático. No entanto, há necessidade de monitorar periodicamente a qualidade da água na sub-bacia.

\section{REFERENCIAS BIBLIOGRÁFICAS}

BRAGA, B.; PORTO, M.; TUCCI, C. E. M. Monitoramento de quantidade e qualidade das águas. In: Rebouças, A. C.; Braga, B.; Tundisi, J. G.(org.). Água doces no Brasil: Capital ecológico, uso e conservação. 3.ed., São Paulo: Escrituras Editoras, 2006. cap.5, p.145-160.

CAI, X.M., MCKINNEY, D.C., ROSEGRANT, M.W. Sustainability analysis for irrigation water management in the Aral Sea region. Agricultural Systems, v.76, n.3, p.1043-1066, 2003

CETESB. Significado ambiental e sanitário das variáveis de qualidade das águas e dos sedimentos e metodologias analíticas e de amostragem. Série Relatórios, CETESB, 2009. 44p. Disponível em <http://www.cetesb.sp.gov.br/userfiles/file/agua /aguas-superficiais/variaveis. pdf > Acesso em 04 Fev2013

FIGUEIRÊDO, A. C. Avaliação e diagnóstico da qualidade da água do açude de apipucos, Recife-PE. Pernambuco, 2008. 104 f. Dissertação (Mestrado em Engenharia Agrícola) - Universidade Federal Rural de Recife.

FONTES, A. L. Caracterização Geoambiental da bacia do rio Japaratuba (SE). Rio Claro, 2003. 298 f. Tese (Doutorado em Geomorfologia) - Instituto de Geociências e Ciências Exatas. Universidade Estadual de São Paulo.

JI, X.B., KANG, E.S., CHEN, R.S., ZHAO, W.Z., ZHANG, Z.H., 2006. The impact of the development of water resources on environment in arid inland river basins of Hexi region, Northwestern China. Environmental Geology, v.50, n.6, p.793-801.

KIZUKA, T., YAMADA, H., YAZAWA, M., CHUNG, H.H., 2008. Effects of agricultural land use on water chemistry of mire pools in the Ishikari Peatland, Northern Japan. Landscape and Ecological Engineering, v.4, n.1, p.27-37.

LORITE-HERRERA, M., JIMENEZESPINOSA, R., 2008. Impact of agricultural activity and geologic controls on groundwater quality of the alluvial aquifer of the Guadalquivir River (province of Jaen, Spain): a case study. Environmental Geology, v.54, n.7, p.1391-1402

MACHADO, R.; AGUIAR NETTO, A.O.; CAMPECHE, L.F.S.M.; BARROS,A.C. Efeito da Salinidade em Características Físico-Hídricas em Solos Salino-Sodilizados no Perímetro Irrigado Jabiberi-SE. Revista Brasileira de Agricultura Irrigada, v.1, n.1, p.15-19, 2007

SCAVIA, D., BRICKER, S.B., Coastal eutrophication assessment in the United States. Biogeochemistry, v.79, n.1-2, p.187-208, 2006

TANJI, K.K., KIELEN, N.C., 2002 Agricultural drainage water management in arid and semiarid areas. Food and Agriculture Organization of the United Nations. Irrigation and drainage paper 61. Rome

TUNDISI, J. G.; TUNDISI, M. T.; ABE, D. S.; ROCHA, O; STARLING, F. Limnologia de águas interiores: impactos, conservação e recuperação de ecossistemas aquáticos. In: Rebouças, A. C.; Braga, B.; Tundisi, J. G. (Org.). Águas doces no Brasil: capital ecológico, uso e conservação (3.ed.). São Paulo: Escrituras Editoras, cap.7, 2006. p.203240. 